\title{
Demographic and dendrochronological evidence reveals highly endangered status of a paleoendemic woody mallow from the Canary Islands
}

\author{
Alejandro G. Fernández de Castro ${ }^{1}$ (D) - Vicente $\operatorname{Rozas}^{2,5}$ (D) Javier Fuertes-Aguilar ${ }^{1}$ (D) . \\ Juan Carlos Moreno-Saiz ${ }^{3,4}$ (D)
}

Received: 5 October 2018 / Revised: 16 October 2019 / Accepted: 26 October 2019 /

Published online: 11 November 2019

(c) Springer Nature B.V. 2019

\begin{abstract}
Navaea phoenicea (Malvaceae) is a flagship shrub species endemic to Tenerife Island in the Canary archipelago and is included as Endangered on the Spanish Red List. We conducted a comprehensive census and monitored the structure of eight accessible populations over 10 years to develop a stage-based demographic matrix model and performed deterministic and stochastic projections. To determine the longevity of individuals, we conducted a dendrochronological study on ten collected dry samples. The censuses showed a clear, gradual decline, and the total population was around half that in previous studies. The yearly finite growth rate was strongly correlated with annual rainfall. Survival rates of seedlings were low, and high elasticity values were allocated to the larger, reproductive individuals, which showed the highest survival rates. The age of the oldest individual was 32 years, while the average age inferred from dendrochronology was 18 years. These results point to a lower longevity of individuals with respect to the values calculated by demographic models. The findings of this study suggest the importance of the preservation of reproductive individuals and their habitat, as well as the need to re-adopt legal measures of greater protection for the species.
\end{abstract}

Keywords Canary Islands · Macaronesian bird-flower element · Matrix modelling · Lavatera $\cdot$ Navaea phoenicea $\cdot$ Malvaceae $\cdot$ Stochastic models

Communicated by David Hawksworth.

Electronic supplementary material The online version of this article (https://doi.org/10.1007/s1053 1-019-01894-6) contains supplementary material, which is available to authorized users.

Alejandro G. Fernández de Castro

jano@rjb.csic.es

Extended author information available on the last page of the article 


\section{Introduction}

The characteristics of volcanic archipelagos make insular biota more vulnerable to extinction due to isolation and limited potential habitat, resulting in a large number of endangered species (Courchamp et al. 2014; Harter et al. 2015). Conservation biology has thus focused on oceanic islands, given the higher species diversity in these small territories (Kier et al. 2009). One paradigmatic case is the Canary archipelago, whose early colonization by African and later European settlers led to a dramatic disturbance of natural habitats (De Nascimento et al. 2009; Fernández-Palacios et al. 2011). The Canary Islands, as part of the Mediterranean-Macaronesian hotspot (Médail and Quézel 1999), hosts a large plant diversity with approximately 50\% of endemic taxa (Reyes-Betancort et al. 2008). The main threats to biodiversity identified in the archipelago include severe habitat reduction combined with strong fragmentation, grazing by introduced herbivores and competition with invasive plant species (Bañares-Baudet et al. 2004; Caujapé-Castells et al. 2010; Gangoso et al. 2006; Sosa et al. 2014). Thus, $25 \%$ of the Canarian flora fall within an IUCN category of risk (Bañares-Baudet et al. 2004; Moreno-Saiz 2008; Moreno-Saiz et al. 2015; Muñoz-Rodríguez et al. 2016). Whereas population genetics (Caujapé-Castells et al. 2010) along with reproductive biology and autecology approaches (Anderson et al. 2015) have accounted for most of the efforts, studies focusing on demographic parameters account to date for little more than a dozen species (Iriondo et al. 2009; Marrero-Gómez et al. 2005, 2007, 2015).

Within the endangered flora of the Canary Islands, we focus on a relic, paleoendemic species. Navaea phoenicea (Malvaceae) is a rare shrubby mallow restricted to reduced areas in Tenerife Island. The species shows a rare bird-pollination system, making it part of the Macaronesian bird flower element (Fernández de Castro et al. 2017). The natural history of the species and its role in the ecosystems makes it a flagship species for conservation measures. N. phoenicea has been recognized either as a vulnerable (Rodríguez Núñez et al. 2004) or endangered taxon (Gómez Campo 1996; Moreno-Saiz 2008) based on IUCN criteria. However, its populations have been downgraded to the legal status of 'Species of special interest for the Canarian ecosystems', a category for unthreatened species managed 'by virtue of their relationship to the ecosystems of the protected areas in which they are located' (Gobierno de Canarias 2010).

Prior evaluations conducted for this plant identified as the main endangerment factors the inability to disperse seeds, grazing, competition with exotic species and habitat loss (Rodríguez Núñez et al. 2004). These risk assessments, however, were based only on visual evidence, which caused them to reach conclusions not supported by longterm studies. Demographic parameters, such as the structure and viability of the populations, are thus far unknown. The aim of this paper is to shed light on these questions to assess the conservation status of the species. For this purpose, a detailed population survey over 10 years was conducted along with a dendrochronological study to perform a population viability analysis (PVA) to determine long-term trends. The objectives were: (1) to model population dynamics and examine which life stages contribute to their growth rates; (2) to assess the relationship between climate and demography; and (3) to model extinction probability to guide conservation strategies. 


\section{Materials and methods}

\section{Study site and species}

Navaea phoenicea represents an independent lineage within the tribe Malveae (Escobar García et al. 2009). It is a large-sized shrub, exemplifying a case of insular woodiness within its lineage (Carlquist 1974; Lens et al. 2013). Flowers are pollinated by non-specialist passerine birds (Fernández de Castro et al. 2017). The seeds are dry schizocarps that disperse mostly by barochory, with germination rates remaining very low without manual scarification.

The habitat of $N$. phoenicea are the steep slopes of the transition between the sclerophyllous forests of the Thermomediterranean dry belt, characterized by the occurrence of Maytenus canariensis, Pistacia atlantica, and Juniperus phoenicea, and the Mesomediterranean subhumid laurel forests, where is frequent the presence of Apollonias barbujana and Visnea mocanera (del Arco Aguilar and Rodríguez Delgado 2018), which has been severely reduced by human activities (del Arco Aguilar et al. 2010). Within these habitats, populations are restricted to northern cliffs of the two old volcanic paleoislands of Tenerife, the Anaga (East) and Teno (West) mountain massifs, resulting in two fragmented population groups composed of eight and seven subpopulations,

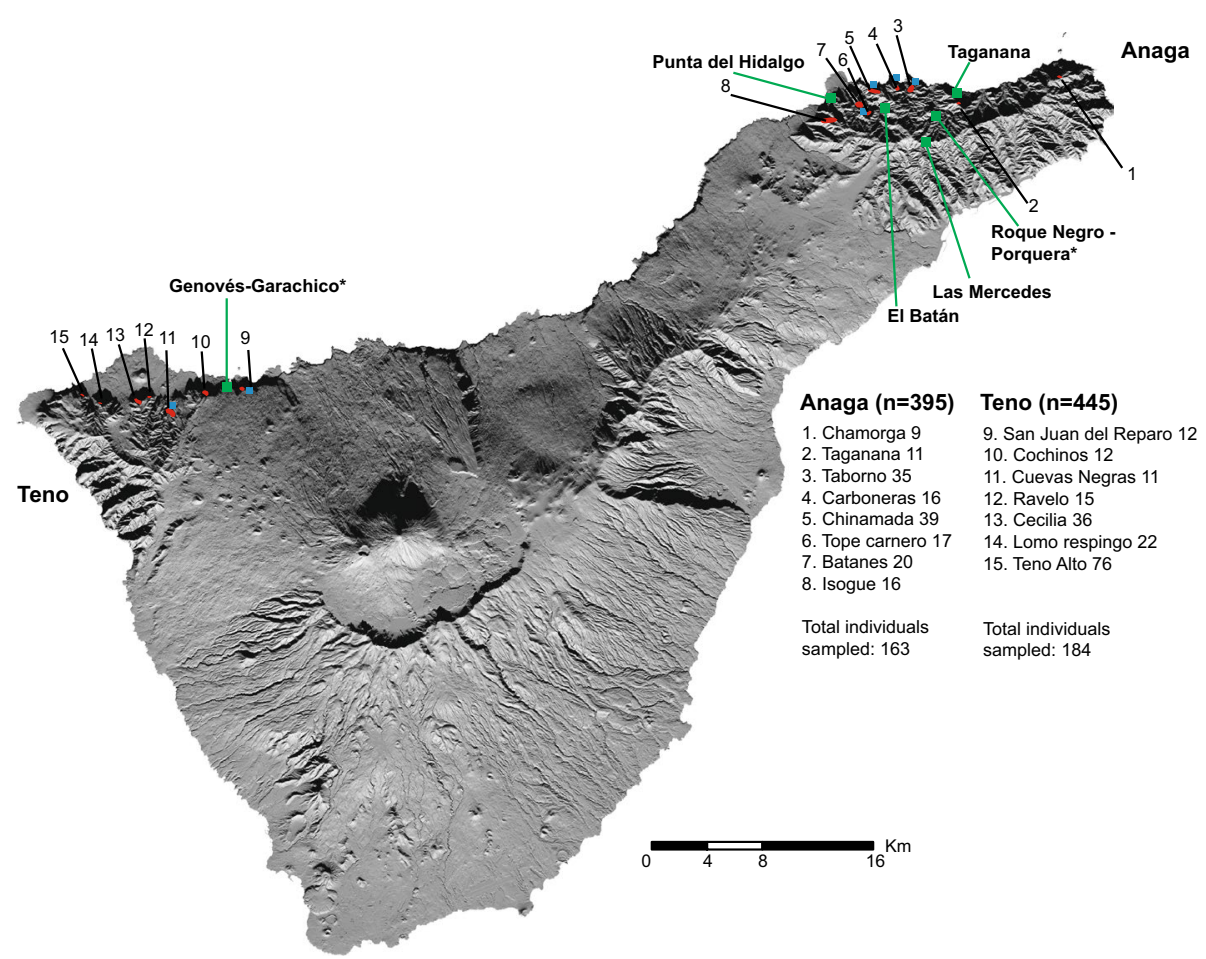

Fig. 1 Location of Tenerife Island, sampling plots (in red) and situation of meteorological stations. Asterisks denote the stations used as individual climate proxies to determine correlations between $\lambda$ and tree ring growth with climatic parameters 
respectively (Fig. 1). A census carried out for the Red Book counted as many as 1410 mature individuals (Rodríguez Núñez et al. 2004).

\section{Demographic survey}

All known subpopulations and nearby areas (Fig. 1) were intensively prospected in January 2006 and all individuals recorded. The inaccessibility and instability of the ravines necessitated the use of binoculars on several occasions. The eight most accessible subpopulations were delimited as survey plots for annual demographic monitoring. All individuals within the plots were tagged, georeferenced, and measured for the following biometric parameters: basal diameter of the stem, total height and crown surface. The cylindrical biovolume was calculated as the product of total height by crown surface. Flower production and number of branches were also quantified. Futher, we calculated the correlations between all biometric parameters to determine if the stem diameter could be considered as a reliable size estimator.

In every annual sampling, from 2006 to 2015, plots were visited in search of new seedlings, and biometric parameters were measured yearly for every recorded individual. Surveys were performed at the end of the flowering season in late February. Reproductive data coupled with biometry were used to establish the threshold between life stages (see results): (1) seedlings (S), considered as first year individuals; (2) juvenile (V); (3) young reproductive (RI) as flowering individuals of stem diameter $<5.8 \mathrm{~cm}$; and (4) mature reproductive (RII), flowering individuals with stem diameter $\geq 5.8 \mathrm{~cm}$. The $5.8 \mathrm{~cm}$ diameter threshold dividing RI and RII classes was selected as the increment in flower production was maximal at this point under a GAM model (see "Results"). These classes were used to estimate the transition matrices for demographic modeling over the period of the study. To account for significant differences in seedling survival between localities and years, generalized linear models (GLM) were employed. For recruitment, we assumed that reproductive capacity was directly proportional to tree size. We therefore used the sum of stem diameters as a covariate in the model following Pierson and Turner (1998). With respect to seedling survival, we fitted a GLM with localities and years as predictors. The fate of seedlings (death or survival the next year) was used as a dependent variable following a binomial distribution.

\section{Deterministic matrix modeling}

Projection matrices to calculate transition probabilities between life stages were built using the popbio package (Milligan and Stubben 2007), implemented in R software ( $\mathrm{R}$ Core Team 2013). To account for fecundity estimates we took the approach of Caswell (2001). First, the seed production of each individual was calculated based on the number of flowers, which was counted weekly in the sampling periods from 2007 to 2009 . The total number of flowers was modeled as a response variable in a linear regression against the basal diameter of the stem. The model was used to estimate the total number of flowers of each individual for subsequent sampling years, where population censuses occurred only at the end of the flowering period. The total number of flowers of each individual was multiplied by the mean number of ovules per flower and the average fructification rate (21 and 0.18, respectively; Fernández de Castro, unpublished results). Second, the average number of seedlings that emerged the next year was divided by the average total number of seeds produced every year, as an estimate of the rate of 
seedlings established per seed. Finally, the number of seeds produced annually by each individual was multiplied by the mean rate of seedling production, as the individual estimate of fecundity. Lefkovitch transition probability matrices were calculated, followed by yearly lambda $(\lambda)$ values of finite growth and bootstrap $\lambda$ values along with elasticity matrices. Analyses were conducted for the ensemble of individuals and separately for the two populations, Teno and Anaga.

\section{Average generation time}

A demographic parameter relevant for population genetic models based on the coalescent and population dynamics is the average generation time. The calculation of this parameter is based on the ages at first and last reproduction ( $\alpha$ and $\omega)$. The average time between generations of repeated reproducers is roughly estimated as $T=(\alpha+\omega) / 2$ (Pianka 2011).

\section{Stochastic simulation of population dynamics}

Stochastic simulations were conducted again with the popbio package, which implements equations for stochastic models from Morris and Doak (2002). To account for potential environmental variability affecting growth rates, three scenarios were developed to assign probabilities to each year. One stable scenario where all yearly matrices were weighted equally; a negative scenario where matrices of years with $\lambda<0$ were given twice the weight of those of years with $\lambda>0$; and a third, positive scenario where conversely, years with positive growth were given double weight in the stochastic simulations. Models were run with 50,000 iterations. Quasi-extinction probabilities were calculated assuming an extinction threshold of $\mathrm{N}=100$ (a reduction of $90 \%$ the censed individuals) and a temporal horizon of 100 years.

\section{Climatic variables}

To calculate the correlation between population growth and climate parameters, datasets of available weather stations from the Spanish Meteorological Agency (AEMET) were collected and filtered by location and time span of climate records. Only stations within the northern slopes of Teno and Anaga massifs within the altitude range of N. phoenicea were considered (400-600 m a.s.1.), one in Teno massif and 5 in Anaga (Fig. 1). Here, the following approach was taken to explore which kind of procedure is more informative about the environmental influence on population growth. On the one hand, only one station was kept as a proxy of the general climate variation for the whole Anaga massif. On the other, data from the five stations were used to interpolate a raster map for each monthly variable for every year at $500 \mathrm{~m}$ resolution. Calculations were conducted using the geoR package in R (Ribeiro and Diggle 2015). The values obtained for the centroid cell of all subpopulations in Anaga were then used as a climate proxy. Monthly, quarterly, average and total annual precipitation values, and maximum, minimum and average monthly temperature in Teno and Anaga separately, were used to test the significance of the correlation between $\lambda$ and climate values. 


\section{Dendrochronological analyses}

Given the current conservation status of the species, only dead individuals were used in the dendrochronological assessment. Samples were obtained from the beginning of the survey to 2009. Stems from dead individuals were sliced at their base and manually sanded and processed to clarify the tree rings in the stem. Then, individual growth rings were counted and measured by means of a Velmex sliding-stage micrometer. For each sample, we measured rings along three radii, and an the average ring width series from every individual was calculated. Those individuals whose year of death was known were used to establish a master chronology. Dead individuals found at the beginning of the study for which death year was unknown, were matched to the highest correlation coefficient with the master chronology. All calculations were performed with the dplR package in R (Bunn 2008).

AEMET meteorological station data were used to explore the relationships between climate time series and stem growth. The set of meteorological records was filtered to select stations accounting for data for the life-time period of the sampled specimens. Finally, two stations were chosen as climate proxies (Fig. 1) for Anaga and Teno specimens. The correlation with annual precipitation was analyzed to explore the effects of climatic variables on growth rate. These correlations were calculated for the annual precipitation of the same year, and for the previous and the two previous years.

\section{Results}

\section{Demographic survey and population dynamics}

The initial survey detected 840 individuals, about half of the 1410 counted in the previous census (Fig. 1). However, the survey in inaccessible locations with binoculars could only account for flowering individuals, but not seedlings or juveniles, which could not be easily detected. The starting number of individuals within the accessible studied plots was 347 in total, 163 from Anaga and 184 from Teno. Annual growth inferred from the differences between diameters measured in consecutive years was on average $1.92 \mathrm{~mm}$ $(\mathrm{SD}=1.01)$. The number of flowers and logarithm of the biovolume were significantly correlated with basal stem diameter $\left(\mathrm{F}=910.5, \mathrm{p}<0.001, \mathrm{R}^{2}=0.857 ; \mathrm{F}=558, \mathrm{p}<0.001\right.$, $\mathrm{R}^{2}=0.780, \mathrm{n}=349$, Supplementary Fig. 1a, b, respectively). Diameter was therefore considered a valid measure to establish size classes and life stages. Proportion of seedling survival in the plots from 1 year to the next ranged from 0 to $100 \%$ with a mean of 0.15 . Survival rate significantly varied between years $\left(\mathrm{F}_{9,147}=5.477, \mathrm{p}=0.0026\right)$ and subpopulations $\left(\mathrm{F}_{12,144}=3.337, \mathrm{p}=0.000046\right)$. For recruitment, the minimum ratio of seedlings emerged/ seeds produced ranged from 0 to $0.587 \times 10^{-3}$. Linear models also detected significant differences for both predictors (sub-population: $\mathrm{F}_{9,147}=3.292 \times 10^{-8}, \mathrm{p}=2.017 \times 10^{-7}$; M year: $\left.\mathrm{F}_{9,144}=5.097 \times 10^{-9}, \mathrm{p}=3.806 \times 10^{-16}\right)$.

\section{Deterministic matrix modeling, fecundity and survival rates}

The average $\lambda$ value for the total population was 0.994 , ranging from 0.982 (2012) to 1.022 (2010) (Table 1, Supplementary Table 1). Bootstrapped values ranged overall from 0.985 to 1 . In Teno and Anaga, the average $\lambda$ was 0.992 and 0.994 , respectively, 
Table 1 Average projection and elasticity matrices, average and minimum-maximum bootstrapped $\lambda$ values for the complete period for Teno, Anaga and the total population ensemble

\begin{tabular}{|c|c|c|c|c|c|c|c|c|c|c|}
\hline \multicolumn{5}{|c|}{ Projection } & \multicolumn{4}{|c|}{ Elasticity } & \multirow[t]{2}{*}{$\lambda$} & \multirow[t]{2}{*}{ BS. $\lambda$} \\
\hline \multicolumn{9}{|c|}{ Teno } & & \\
\hline & S & $\mathrm{J}$ & RI & RII & $\mathrm{S}$ & $\mathrm{J}$ & RI & RII & 0.992 & \multirow{6}{*}{$\begin{array}{l}0.985 \\
1.000\end{array}$} \\
\hline S & 0.000 & 0.000 & 0.092 & 0.284 & 0.000 & 0.000 & 0.010 & 0.010 & & \\
\hline V & 0.185 & 0.7599 & 0.000 & 0.000 & 0.020 & 0.065 & 0.000 & 0.000 & & \\
\hline RI & 0.000 & 0.192 & 0.963 & 0.000 & 0.000 & 0.020 & 0.653 & 0.000 & & \\
\hline RII & 0.000 & 0.000 & 0.016 & 0.946 & 0.000 & 0.000 & 0.012 & 0.210 & & \\
\hline $\mathrm{N}$ & 1 & 4.71 & 21 & 30 & & & & & & \\
\hline \multicolumn{11}{|c|}{ Anaga } \\
\hline$S$ & 0.000 & 0.000 & 0.083 & 0.297 & 0.000 & 0.000 & 0.002 & 0.013 & \multirow[t]{5}{*}{0.994} & \multirow{5}{*}{$\begin{array}{l}0.937 \\
1.000\end{array}$} \\
\hline V & 0.110 & 0.787 & 0.000 & 0.000 & 0.016 & 0.062 & 0.000 & 0.000 & & \\
\hline RI & 0.000 & 0.158 & 0.951 & 0.001 & 0.000 & 0.016 & 0.386 & 0.000 & & \\
\hline RII & 0.000 & 0.000 & 0.0375 & 0.966 & 0.000 & 0.000 & 0.014 & 0.486 & & \\
\hline $\mathrm{N}$ & 1 & 4.18 & 27.30 & 18.63 & & & & & & \\
\hline \multicolumn{11}{|c|}{ Total } \\
\hline S & 0.000 & 0.000 & 0.089 & 0.291 & 0.000 & 0.000 & 0.006 & 0.012 & \multirow[t]{5}{*}{0.994} & \multirow{5}{*}{$\begin{array}{l}0.962 \\
1\end{array}$} \\
\hline V & 0.153 & 0.775 & 0.000 & 0.000 & 0.010 & 0.067 & 0.000 & 0.000 & & \\
\hline RI & 0.000 & 0.177 & 0.959 & 0.000 & 0.000 & 0.002 & 0.523 & 0.000 & & \\
\hline RII & 0.000 & 0.000 & 0.024 & 0.957 & 0.000 & 0.000 & 0.013 & 0.339 & & \\
\hline $\mathrm{N}$ & 1 & 4.44 & 24.65 & 23.54 & & & & & & \\
\hline
\end{tabular}

$S$ seedling, $J$ juvenile, $R I$ young reproductive, $R I I$ mature reproductive. $N$ mean time spent in each stage

and bootstrapped values ranged from 0.937 to 1 in Teno, and 0.962 to 1 in Anaga. Three transitions showed $\lambda>1$ in Anaga (2009-2010, 2010-2011 and 2014-2015), two in Teno (2009-2010, 2013-2014), and one for the ensemble (2009-2010). Figure 2a represents the values of fecundity, transition rate to the next stage and survival rates within a given stage. No reversion to previous stages was observed over 10 years. Survival rates were higher in the reproductive stages. The transition from seedling to juvenile, i.e., seedling survival, showed low values $(0.153)$. Fecundity was higher in mature reproductive individuals RII than in young reproductive individuals RI (Table 1). As a result of an average $\lambda<1$, the deterministic matrix model projected a population decrease (Fig. 2b). The current population structure differed from the stable structure defined by the population matrix only between RI and RII individuals as the distributions of their proportions became inverted. Distributions of seedlings and juvenile individuals decreased slightly (Fig. 2b). The time spent in each stage by an individual, estimated from the projection matrix, indicated that $N$. phoenicea is a long-lived species: by definition 1 year in the seedling stage, and an average of 4 years in the juvenile stage, 24 as young reproductive and 25.5 as mature reproductive. This was in sum 55 years. The times estimated for the mature reproductive stage were mostly less in Anaga (18 years) than in Teno (30 years). Average generation time for $N$. phoenicea is $\mathrm{T}=16.8$ years.

Elasticities were high for the survival of young reproductive and mature reproductive individuals. More frequently, annual elasticity matrices assigned higher values to the survival of young reproductive individuals than to mature ones. However, these values varied widely, i.e. in several periods elasticity of survival of mature individuals reached 1 , while 
(a) Life cycle of Navaea phoenicea
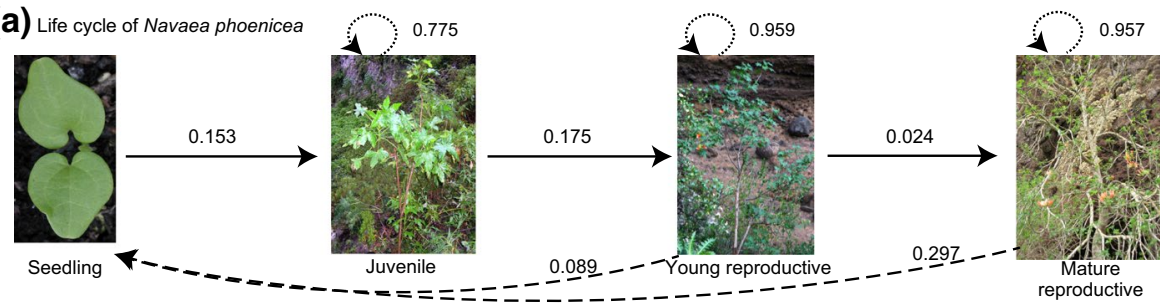

(b) Deterministic trajectories
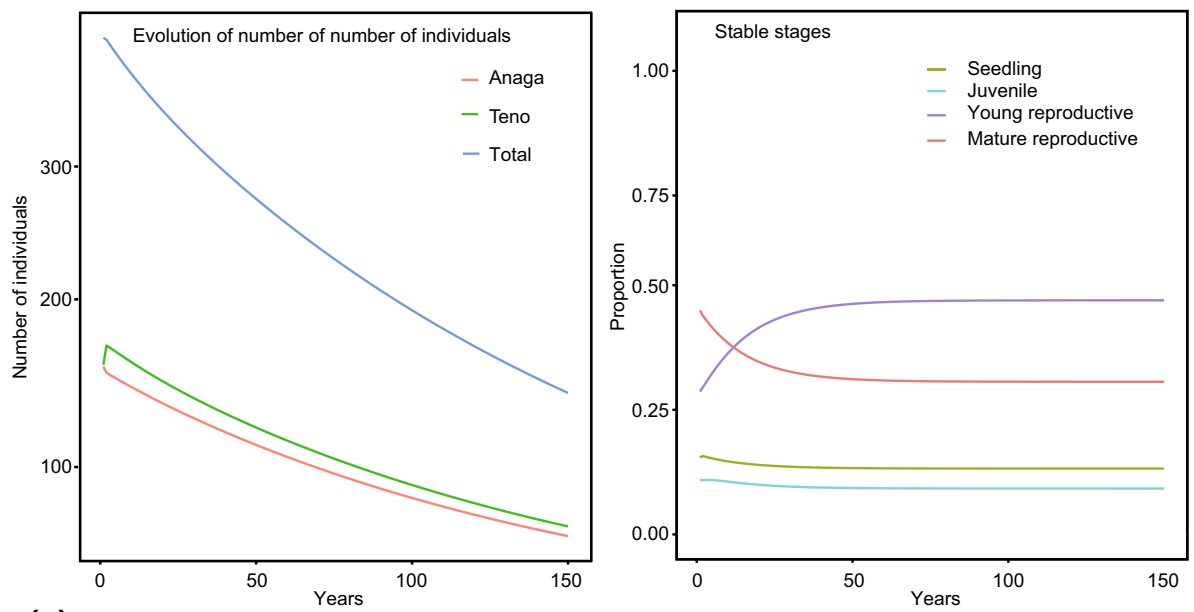

(C) Variation of lambda values and precipitation across years

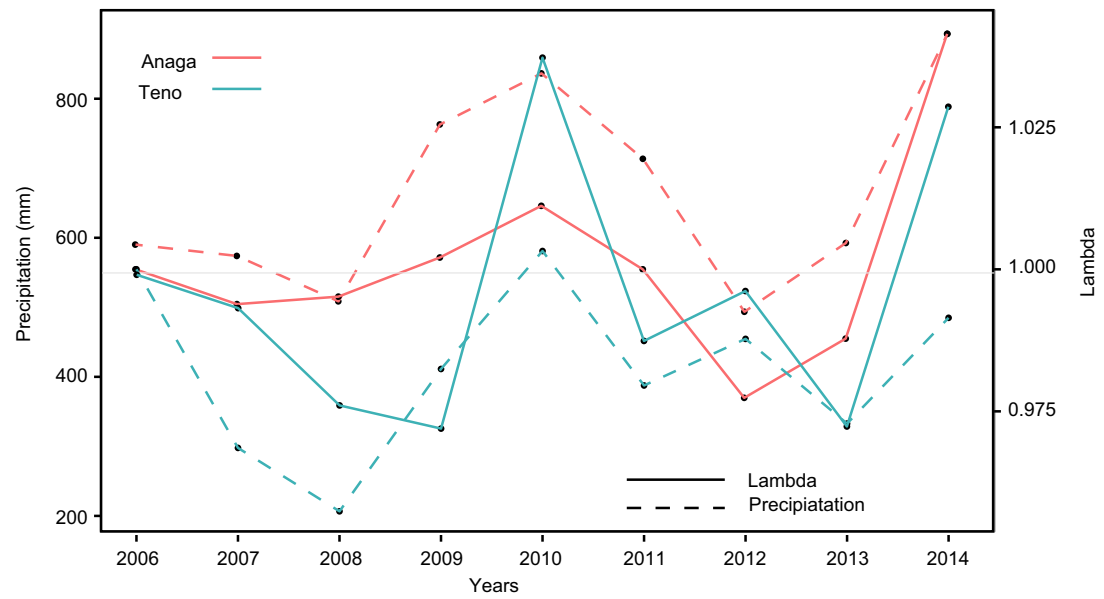

Fig. 2 a Life cycle of Navaea phoenicea. Dashed lines represent fecundity, dotted lines represent survival, and solid lines represent transitions to the next stage; $\mathbf{b}$ deterministic trajectory projection of $N$. phoenicea monitored populations from the number of individuals in 2015 for a period of 150 years; $\mathbf{c}$ yearly $\lambda$ growth rates for Anaga and Teno populations (black line) and yearly total precipitation values for meteorological stations (dashed lines) 
in others, conversely, young reproductive individuals also achieved a value of elasticity of 1. The elasticity of transition between stages or fecundity showed very low values.

No monthly variables of temperature or precipitation presented significant correlations with yearly $\lambda$ values. On the contrary, total annual precipitation showed a strong relationship with $\lambda$ (Fig. 3). In Teno, Pearson $\mathrm{R}^{2}$ was $0.764(\mathrm{t}=3.35$, $\mathrm{df}=8, \mathrm{p}=0.0109)$. In Anaga, where two distinct approaches were used, results differed. In contrast with Teno, there was a weak correlation for a single station $\left(\mathrm{R}^{2}=0.401, \mathrm{t}=1.24, \mathrm{df}=8, \mathrm{p}=0.249\right)$. For the centroid of the interpolated values, however, correlation was strong $\left(R^{2}=0.818, t=4.026\right.$, $\mathrm{df}=8, \mathrm{p}=0.004)$.

\section{Stochastic projections}

Table 2 summarizes stochastic projections under the defined negative, stable and positive scenarios for a temporal horizon of 100 years. Growth rates calculated for stochastic projections showed that at any of the three defined scenarios, both in total and for each population, their values were always $<1$, although in the positive scenario $\lambda$ was 0.999 . Quasi-extinction probabilities varied between scenarios (Supplementary Fig. 2, Table 2). Under the negative scenario, the probability was over 0.938 in all cases. Under the stable scenario, probability in both Teno and Anaga was over 0.973 when considered separately, but not when considered together (0.154). Finally, the positive scenario gave a null probability of quasi-extinction to the population ensemble, low for Teno (0.184) and intermediate for Anaga (0.570). For shorter time horizons, the probabilities for the two populations separately began to increase after 25 years, not before.

Projected population numbers at the end of the simulations were highly variable (Supplementary Fig. 2). For both Anaga and Teno considered separately, in only the positive scenario was the most probable number of effectives over 100. Accounting for the total population, the most probable population numbers were 121 in the negative scenario, 181 in the stable, and 315 in the positive scenario.

\section{Dendrochronological analyses}

Ten samples from dead individuals were obtained during the time period 2005-2008, eight in Anaga and two in Teno. Two dry individuals were found at the beginning of the fieldwork, while the other eight were collected during the annual population sampling. Although the tree-ring chronological series were generally very short (Supplementary Fig. 2), growth rings are characterized by semi-ring porosity and the boundaries can be unequivocally identified by a band of marginal parenchyma (Supplementary Fig. 2). The oldest sample was REP01 at 32 years and the youngest was TAB04 at 11 years. The mean age of sampled individuals inferred from rings was 18.09 , below the times inferred from the projection matrix. On average, annual growth rate was $2.011 \mathrm{~mm}(\mathrm{SD}=1.17)$, slightly higher than growth rate measured at the stem base. Pearson correlation among the individual growth rates was 0.61 .

Correlations between average ring growth per population and any of the time series of annual precipitation were very weak (Supplementary Table 2). Supplementary Fig. 2 shows the relationship between ring growth and total precipitation for the period 1978-2010. In Anaga, the correlation between growth and precipitation only appeared to be significant in the period 1999-2001, and in Teno between 2004 and 2006. However, in some parts of the chronological series, a time lag in the covariation between rainfall and growth could be 
Fig. 3 a Complete transversal section of a stem with visible rings; $\mathbf{b}$ detail of three rings with two tree-ring boundaries. Arrows indicate visible limits between rings; c index of growth per individual through time. Dashed lines represent total precipitation. Grey frames show years with high correlation between growth and precipitation. Arrows indicate possible time offsets in the potential relationship between precipitation and growth, if it actually happens. $\mathbf{d}$ Growth rate index for all the individuals sampled

observed, suggesting that a stronger relationship between climate and growth may occur, but weakly coupled and with a certain preconditioning of climate on growth rates variable across years.

\section{Discussion}

This study provides a census of $N$. phoenicea and a long-term population survey predicting a slow decline of the species in the coming decades. These concerning results offer insights both on the size structure of the population and the effect of climate constraints on population trends. The study on this particular endemic species in the thermophilous shrubland of Tenerife contributes to the understanding of its risk factors and offers clues for the management of the habitat.

\section{Size and population structure}

There is a large discrepancy between the census in our study and a previous one taken for the Spanish Red Book (Rodríguez Núñez et al. 2004). Our number is just over half of the individuals previously estimated. Based on the number of mature individuals, this new census would qualify the species as threatened in the IUCN category VU D1. Such an effective decrease is not likely to have happened, given the slow decline trend found here and the near absence of dead mature individuals at the beginning of our study. Instead, discrepancies are more likely due to the use of different estimation methods and the existence of look-alike species at the same locations.

The sample size that could be surveyed within plots represent a fraction of approximately half of the total census. The population structure based on size in $N$. phoenicea was dominated fundamentally by mature individuals. Because in most years annual surveys were performed once, it is very likely that annual data only accounts for a fraction of total seedlings in the population, although the sampling time was chosen to maximize the number of seedlings emerged from the seed bank. Accounting for the total number of seedlings emerged throughout the year may confer to the species population the classical J-shaped distribution curve of frequency of each stage. Under this 4 stage-based classification of individuals, collected data would classify the populations as 'senile' (Oostermeijer et al. 1994). Juvenile individuals were present in very low numbers and were scarcer than seedlings. One of the main threats to the Canarian flora is grazing, which may more intensely affect seedlings, yet for $N$. phoenicea the elasticity values for seedling survival does not ensure the persistence of the species.

\section{Projected population trends and drivers: reasons for concern?}

The variability of finite growth rate across years and locations was below one, indicating a declining tendency. This trend is partly due to the longevity and relatively slow 

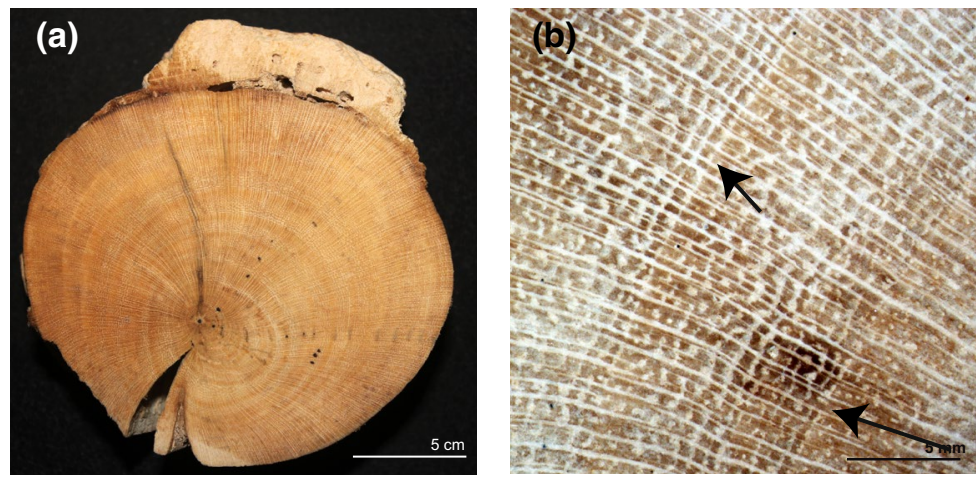

(c)
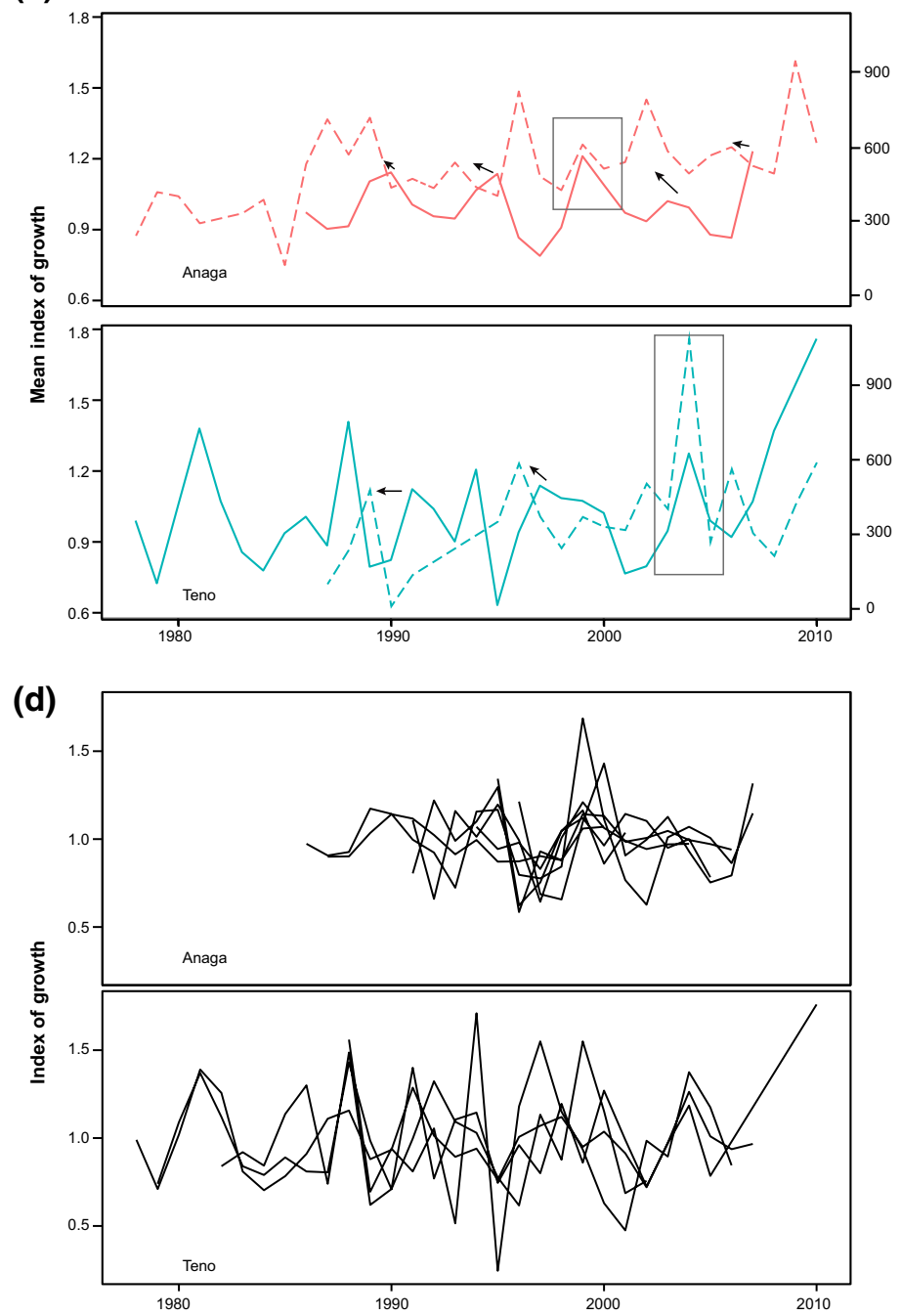
Table 2 Results of stochastic projections for a 150 year horizon

\begin{tabular}{llll}
\hline & Negative scenario & Stable scenario & Positive scenario \\
\hline Teno & & & \\
$\lambda$ & 0.989 & 0.993 & 0.999 \\
Projected population numbers & $25 \pm 8$ & $57 \pm 20$ & $163 \pm 59$ \\
quasi-extinction probability & 0.99 & 0.973 & 0.184 \\
Anaga & & & 0.994 \\
$\lambda$ & 0.990 & 0.993 & $101 \pm 18$ \\
Projected population numbers in 150 years & $45 \pm 8$ & $63 \pm 11$ & 0.570 \\
quasi-extinction probability & 1.000 & 0.997 & 0.999 \\
Total & & & $315 \pm 67$ \\
$\lambda$ & 0.990 & 0.994 & 0.000 \\
Projected population numbers (mean \pm SD) & $121 \pm 22$ & $181 \pm 37$ & 0.154 \\
quasi-extinction probability & 0.938 & & \\
\hline
\end{tabular}

Approximate $\lambda$ values and projected number of effectives are displayed in bold between the $95 \%$ confidence interval. For quasi-extinction probabilities, only the mean value is provided as variation was almost 0 in the three scenarios

growth of individuals, which drives small variations in population numbers and transitions between years. The deterministic modeling predicted less than 100 individuals within the next century meaning a reduction of $30 \%$ of the population in 50 years, insufficient to be considered threatened under IUCN criteria.

The comprehensive COMPADRE database (Salguero-Gómez et al. 2015) shows that other pertinent PVAs are scarce for the Malvaceae. Similarly, there have only been 14 PVAs carried out in Canarian plants (Iriondo et al. 2009; Kyncl et al. 2006; MarreroGómez et al. 2005, 2007), across all environments. Demographic monitoring on Canarian species has shown great variations in their population trends, ranging from $\lambda=0.603$ for Laphangium teydeum (Asteraceae, Marrero-Gómez et al. 2015) to $\lambda=1.247$ for Helianthemum juliae Wildpret (Cistaceae, Marrero-Gómez et al. 2007), both endemic to the Cañadas del Teide National Park in Tenerife. N. phoenicea showed an intermediate $\lambda=0.994$ and by far the lowest fluctuation in annual population growth trends among the studied Canarian taxa. For these three species, as for some others, the highest elasticities were associated with survival rates of mature individuals. Likewise, survival of juvenile individuals was associated with rainfall amounts.

Accounting for stochasticity under different scenarios of population growth, only the positive scenario did not predict an early quasi-extinction event. The probabilities are dependent on two arbitrary inputs, namely the time period for the calculation and the initial number of individuals. The models were run accounting only for individuals within survey plots, which represent approximately $50 \%$ of the total estimated population, thus the actual quasi-extinction probability should be lower. In the three scenarios, however, the average stochastic $\lambda$ was always below 1 , indicating a likely decrease in the number of effectives regardless of the environmental variability. Stochastic models allow for the assessment of IUCN criterion E for probability of extinction within a time period. Given the long lifespan of cohorts estimated by the matrix models, extinction probability would only increase significantly after 25 years, but in the time period 
within 5 generations. Therefore, $N$. phoenicea should be included in EN category under this criterion, i.e. $>20 \%$ of extinction probability in less than 20 years or 5 generations.

The causes of the decline may be twofold. First, demographic analysis showed a strong relationship between precipitation and $\lambda$, where years with precipitation $>550 \mathrm{~mm}$ drove a positive population growth. Overall, the elasticity analysis showed that individual reproductive stages are crucial for the survival of populations as they had significantly higher values than any transition or fecundity values in the average matrices. On the other hand, the congruence between recruitment and rainfall has been found for other species in different climate regimes and habitats in Tenerife (Fernández-Lugo et al. 2015; Marrero-Gómez et al. 2007). This evidence is consistent with the fact that juveniles show a high survival rate; once the critical seedling stage is passed. A second possible factor is seedling predation as a direct driver against recruitment.

Although grazing is considered a recurrent risk factor for the Canarian flora (Gangoso et al. 2006; Moreno-Saiz et al. 2015), our evidence for this is uncertain, especially confronted with findings for the noticeable effect of rainfall. In a preliminary experiment performed between exclusion and non-exclusion plots, we found significant differences in recruitment, but the small sample size and short-term nature of the assay prevents sound conclusions. Because recruitment and seed survival vary significantly between populations and years, there may be several local factors affecting recruitment.

The high elasticity attributed to reproductive individuals indicates a requirement for the conservation of the species, which can be translated into recommendations for habitat conservation. This presents challenges for decision-makers, as land management on islands can be particularly difficult (Fernandes et al. 2015). However, under the current trend of populations and probabilities this may not be enough in the long term. Since recruitment appears to rely largely on climate, it is necessary to assess current and future trends of precipitation. Trends from preindustrial times until the present show a significant decrease in the precipitation for the Canary Islands when measuring tendencies at the regional scale (Niang et al. 2013) but not significant at the Macaronesian scale (Cropper and Hanna 2014). Projections of IPCC5 scenarios (IPCC 2013) predict a significant decrease in the rainfall of $20 \%$ by 2100 under the worst emissions scenario. IPCC 5 scenarios have not been downscaled for the Canary Islands, which is needed given the complexity of climate in oceanic islands when representing microclimate variables that operate at finer scales (Harter et al. 2015). For instance, the effect of trade winds, which are crucial for rainfall regime and water balance, may be very difficult to model for the present climate and to downscale future scenarios. Specifically, a downward shift of the cloud forest has been predicted resulting from the incidence of trade winds (Sperling et al. 2004), which would in turn favor populations of $N$. phoenicea if rainfall is increased in the lower limit of its altitudinal range. On the other hand, the species distribution shows a certain altitudinal variation, with subpopulations located at the lower edge of the thermophilous shrubland limited by the coastal desert, and others near or within the laurel forest, although a sufficient sampling size could not be retrieved to test the effect of elevation on the growth rate apportioned by subpopulations. Therefore, the fate of populations may be asymmetric depending on the distribution under scenarios of intense climate change, but can present an opportunity to carry out assisted migration.

\section{Coupling dendrochronology and population viability analysis}

Although evolutionary implications of insular woodiness in $N$. phoenicea are beyond the scope of this paper, accounting for tree rings and stem growth allowed us to confirm the 
existence of true woodiness in a species disregarded in previous studies (Lens et al. 2013). Rings can be easily visualized and measured. Because of the conservative approach to an endangered species, sample size achieved throughout the period was very low, and therefore these results should be considered with caution.

The correlation between chronological series was satisfactory, but there was weak evidence of the effect of climatic variables on tree growth. Microclimatic variations linked to complex topography are a generalized factor in oceanic islands (Harter et al. 2015; Irl et al. 2015). Therefore, the climate proxies may misrepresent the local climatic conditions that affect tree growth. Similar results are found for tree species (Rozas et al. 2013). Measures of annual growth taken in the sampling plots were inconsistent with width increments measured from tree rings. There was no correlation between age and basal diameter. Age therefore, as often occurs in the vast majority of species studied, can be considered a poor predictor of the reproductive ability of individuals, which is in turn rather correlated with size. A second incongruence found between matrix modeling and this dendrochronological study is their difference in the survival rates. Even with the limited sample size, the mean age of dead individuals was 18 years and the oldest individual, which also had the second largest trunk, was 32. On the contrary, the matrix modeling gave much higher estimates of survival in each stage. One possible explanation is that individuals in the dendrochronological study were sampled in more optimal years. Since conservation strategies rely partially on the assurance of survivorship of the largest individuals, this incongruence must be taken into account as a caution measure, if living times extracted by matrix modeling are overestimated.

\section{Concluding remarks for conservation strategies}

This study identifies a population decline driven by a lack of recruitment in the driest years, which were frequent in the survey period. The application of IUCN criteria through this study provides evidence to maintain Navaea phoenicea in the EN category. Our study calls into question the justification for the reduction in its protection and, on the contrary, warns about the future of a plant whose habitats are fragmented and unprotected or covered by 'low intensity' figures of land protection (Rural Park and Protected Landscape). Projected governmental evaluation in 2018 (A. Bañares com. pers.) should incorporate these new data and draw up a recovery plan in line with the real risks faced by the species.

The rate of decline, although clear, is modulated by the long lifespan cycle of the species. Even in the absence of this risk of rapid decay, which would better suggest a longterm conservation strategy, it is necessary to address the remaining risk factors. Population numbers are very low and subject to catastrophic events as the stochastic models showed. These may be natural processes frequent in the oceanic archipelagos, such as landslides or volcanic episodes, but can also be human-induced impacts. An ex situ reproduction program, as well as an adequately storage of genotyped germplasm, could act as a supporting measure in the event of climate-change related hazards, such as prolonged drought or a source of population reinforcement programs. This was already suggested by Rodríguez-Núñez et al. (2004) for some localities. There are currently three germoplasm banks hosting seeds (Jardín Botánico Viera y Clavijo in Gran Canaria island, and Real Jardín Botánico, in Madrid). The first two preserve live individuals. Besides, other individuals are maintained by private initiatives with no information of their origin. Grazing, together with non-climatic factors affecting seedling survival for instance, must be still investigated accurately. Habitat preservation and competition with invasive species must be addressed 
as well, as part of the conservation practices for reproductive individuals and to acknowledge natural and anthropogenic mortality causes. Climate-induced changes in vital rates may be more difficult to manage. Besides an assisted approach, habitat conservation should not only contribute to the preservation of reproductive individuals, it should preserve bird pollinators and ensure reproductive fitness, which may improve with higher visit rates of efficient pollinators. Although time-consuming, PVAs prove to be useful for a better understanding of the risk factors that threaten populations. Given the singularity of the island biota and the conservation status, it is therefore necessary to improve the use of these methods.

Acknowledgements This research was funded by the CSIC Intramural project 2006-3-OI-028, Spanish Ministry of Science and Innovation research project CGL2007-66516 to JFA and a personal grant FPI 0266/2005 from Madrid Regional Government (European Social Fund) to AGFdC. We thank Mar Génova, for her help in the dendrochronological field work. We also thank Cabildo de Tenerife and Gobierno de Canarias for permissions for sampling and prospection. The Agencia Estatal de Meteorología (AEMET) kindly provided meteorological data. The authors are grateful to Txema Iriondo for his comments on this paper.

\section{References}

Anderson GJ, Bernardello G, Santos-Guerra A (2015) Reproductive biology of Solanum vespertilio (Solanaceae), a zygomorphic, heterantherous, enantiostylous, and andromonoecious rare Canary Islands endemic. Plant Syst Evol 301:1191-1206. https://doi.org/10.1007/s00606-014-1143-4

Bañares-Baudet Á, Blanca G, Güemes J et al (2004) Atlas y Libro Rojo de la Flora Vascular Amenazada de España. Dirección General de Conservación de la Naturaleza, Madrid

Bunn AG (2008) A dendrochronology program library in R (dplR). Dendrochronologia 26:115-124. https:// doi.org/10.1016/j.dendro.2008.01.002

Carlquist S (1974) Insular woodiness. Island Biology. Columbia University Press, New York, pp 350-428

Caswell H (2001) Matrix population models: construction, analysis and interpretation, 2nd edn. Sinauer, Sunderland

Caujapé-Castells J, Tye A, Crawford DJ et al (2010) Conservation of oceanic island floras: present and future global challenges. Perspect Plant Ecol Evol Syst 12:107-129. https://doi.org/10.1016/j.ppees .2009.10.001

Courchamp F, Hoffmann BD, Russell JC et al (2014) Climate change, sea-level rise, and conservation: keeping island biodiversity afloat. Trends Ecol Evol 29:127-130. https://doi.org/10.1016/j.tree.2014.01.001

Cropper TE, Hanna E (2014) An analysis of the climate of Macaronesia, 1865-2012. Int J Climatol 34:604622. https://doi.org/10.1002/joc.3710

De Nascimento L, Willis KJ, Fernández-Palacios JM et al (2009) The long-term ecology of the lost forests of la Laguna, Tenerife (Canary Islands). J Biogeogr 36:499-514. https://doi.org/10.111 $1 / \mathrm{j} .1365-2699.2008 .02012 . x$

del Arco Aguilar MJ, Rodríguez Delgado O (2018) Vegetation of the Canary Islands. Plant and vegetation, vol 16. Springer, Cham. https://doi.org/10.1007/978-3-319-77255-4

del Arco Aguilar MJ, González-González R, Garzón-Machado V, Pizarro-Hernández B (2010) Actual and potential natural vegetation on the Canary Islands and its conservation status. Biodivers Conserv 19:3089-3140. https://doi.org/10.1007/s10531-010-9881-2

Escobar García P, Schönswetter P, Fuertes Aguilar J et al (2009) Five molecular markers reveal extensive morphological homoplasy and reticulate evolution in the Malva alliance (Malvaceae). Mol Phylogenet Evol 50:226-239. https://doi.org/10.1016/j.ympev.2008.10.015

Fernandes JP, Guiomar N, Gil A (2015) Strategies for conservation planning and management of terrestrial ecosystems in small islands (exemplified for the Macaronesian Islands). Environ Sci Policy 51:1-22. https://doi.org/10.1016/j.envsci.2015.03.006

Fernández de Castro AG, Moreno-Saiz JC, Fuertes-Aguilar J (2017) Ornithophily for the nonspecialist: differential pollination efficiency of the macaronesian island paleoendemic Navaea phoenicea (Malvaceae) by generalist passerines. Am J Bot 104:1556-1568. https://doi.org/10.3732/ajb.1700204 
Fernández-Lugo S, de Nascimento L, Méndez J et al (2015) Seedling survival patterns in Macaronesian laurel forest: a long-term study in Tenerife (Canary Islands). Forestry 88:121-130. https:// doi.org/10.1093/forestry/cpu035

Fernández-Palacios JM, De Nascimento L, Otto R et al (2011) A reconstruction of Palaeo-Macaronesia, with particular reference to the long-term biogeography of the Atlantic island laurel forests. J Biogeogr 38:226-246. https://doi.org/10.1111/j.1365-2699.2010.02427.x

Gangoso L, Donazar JA, Scholz S et al (2006) Contradiction in conservation of island ecosystems: plants, introduced herbivores and avian scavengers in the Canary Islands. Biodivers Conserv 15:2231-2248. https://doi.org/10.1007/s10531-004-7181-4

Iriondo JM, Albert MJ, Giménez-Benavides L, et al. (2009) Poblaciones en peligro: Viabilidad demográfica de la Flora Vascular Amenazada de España, 1st ed. Dirección General de Medio Natural y Política Forestal (Ministerio de Medio Ambiente, y Medio Rural y Marino), Madrid

Gobierno de Canarias (2010) Catálogo Canario de especies protegidas. 167:16

Gómez Campo, C. (Ed.) 1996. Libro Rojo de Especies Vegetales Amenazadas de las Islas Canarias. Gobierno de Canarias, Tenerife

Harter DEV, Irl SDH, Seo B et al (2015) Impacts of global climate change on the floras of oceanic islands-projections, implications and current knowledge. Perspect Plant Ecol Evol Syst 17:160183. https://doi.org/10.1016/j.ppees.2015.01.003

IPCC Working Group I (2013) IPCC fifth assessment report (AR5) - the physical science basis. Cambridge University Press, Cambridge, p 1535

Irl SDH, Harter DEV, Steinbauer MJ et al (2015) Climate vs. topography-spatial patterns of plant species diversity and endemism on a high-elevation island. J Ecol 103:1621-1633. https://doi. org/10.1111/1365-2745.12463

Kier G, Kreft H, Lee TM et al (2009) A global assessment of endemism and species richness across island and mainland regions. Proc Natl Acad Sci USA 106:9322-9327. https://doi.org/10.1073/ pnas.0810306106

Kyncl T, Suda J, Wild J et al (2006) Population dynamics and clonal growth of Spartocytisus supranubius (Fabaceae), a dominant shrub in the alpine zone of Tenerife, Canary Islands. Plant Ecol 186:97-108. https://doi.org/10.1007/s11258-006-9115-6

Lens F, Davin N, Erik Smets, del Arco M (2013) Insular woodiness on the Canary Islands: a remarkable case of convergent evolution. Int J Plant Sci 174:992-1013

Marrero-Gómez MV, Bañares-Baudet Á, Carqué-Álamo E (2005) Viabilidad de las poblaciones del endemismo tinerfeño Echium auberianum (Boraginaceae). Vieraea 33:93-104

Marrero-Gómez MV, Oostermeijer JGB, Carqué-Âlamo E, Bañares-Baudet Á (2007) Population viability of the narrow endemic Helianthemum juliae (Cistaceae) in relation to climate variability. Biol Conserv 136:552-562. https://doi.org/10.1016/j.biocon.2007.01.010

Marrero-Gómez MV, Bañares-Baudet Á, Carqué-Álamo E (2015) Seguimiento de la flora vascular de España. Bencomia de cumbre (Bencomia exstipulata). Amagante de roques (Cistus chinamadensis). Borriza del Teide (Laphangium teydeum). Saúco canario (Sambucus nigra ssp. palmensis). Canutillo del Teide (Silene nocteole). Dirección General de Calidad y Evaluación Ambiental y Medio Natural, Ministerio de Agricultura, Alimentación y Medio Ambiente., Madrid

Médail F, Quézel P (1999) Biodiversity hotspots in the Mediterranean Basin: setting global conservation priorities. Conserv Biol 13:1510-1513

Milligan BG, Stubben CJ (2007) Estimating and analyzing demographic models using the popbio package in R. J Stat Softw 22(11):1-23

Moreno-Saiz JC (2008) Lista Roja de Flora Vascular Española. Dirección General de Medio Natural y Política Forestal (Ministerio de Medio Ambiente, y Medio Rural y Marino, y Sociedad Española de Biología de la Conservación de Plantas), Madrid

Moreno-Saiz JC, Domínguez Lozano F, Marrero-Gómez MV, Bañares-Baudet Á (2015) Application of the Red List Index for conservation assessment of Spanish vascular plants. Conserv Biol 29:910919. https://doi.org/10.1111/cobi.12437

Morris WF, Doak DF (2002) Quantitative conservation biology: theory and practice of population viability analysis. Sinauer Associates, Sunderland

Muñoz-Rodríguez P, Munt DD, Saiz JCM (2016) Global strategy for plant conservation: inadequate in situ conservation of threatened flora in Spain. Isr J Plant Sci 63:297-308. https://doi. org/10.1080/07929978.2016.1257105

Niang I, Ruppel OC, Abdrabo MA, et al. (2014) Africa. In: Barros VR, Field CB, Dokken DJ, et al. (eds) Clim. Chang. 2014 Impacts, Adapt. Vulnerability. Part B Reg. Asp. Contrib. Work. Gr. II to Fifth Assess. Rep. Intergov. Panel Clim. Chang. Cambridge University Press, Cambridge, pp 1199-1265 
Oostermeijer JGB, Vantveer R, Dennijs JCM et al (1994) Population-structure of the rare, long-lived perennial Gentiana pneumonanthe in relation to vegetation and management in the Netherlands. J Appl Ecol 31:428-438

Pianka ER (2011) Evolutionary Ecology eBook, 7th edition. Google Books

Pierson EA, Turner RM (1998) An 85-year study of saguaro (Carnegiea gigantea) demography. Ecology 79:2676-2693. https://doi.org/10.1890/0012-9658(1998)079\%5b2676:aysosc\%5d2.0.co;2

R Core Team (2013) R: a language and environment for statistical computing. Version 3.1.2. R Core Team, Vienna

Reyes-Betancort JA, Santos Guerra A, Guma IR et al (2008) Diversity, rarity and the evolution and conservation of the Canary Islands endemic flora. An Jard Bot Madrid 65:25-45. https://doi.org/10.3989/ ajbm.2008.v65.i1.244

Ribeiro PJ, Diggle PJ (2015) geoR: Analysis of Geostatistical Data

Rodríguez Núñez S, Acevedo Rodríguez A, Oval de la Rosa JP et al (2004) Lavatera phoenicea Vent. In: Bañares-Baudet Á, Blanca G, Güemes J et al (eds) Atlas y Libro. Rojo la Flora Vascular Amenazada de España. Dirección General de Conservación de la Naturaleza, Madrid, p 895

Rozas V, García-González I, Pérez-De-Lis G, Arévalo JR (2013) Local and large-scale climatic factors controlling tree-ring growth of Pinus canariensis on an oceanic island. Clim Res 56:197-207. https://doi. org/10.3354/cr01158

Salguero-Gómez R, Jones OR, Archer CR et al (2015) The compadre Plant Matrix Database: an open online repository for plant demography. J Ecol 103:202-218. https://doi.org/10.1111/1365-2745.12334

Sosa PA, González-González EA, González-Pérez MA et al (2014) Reproductive strategy and ploidy determine the genetic variability of Sorbus aria. Tree Genet Genomes 10:679-688. https://doi.org/10.1007/ s11295-014-0713-5

Sperling FN, Washington R, Whittaker RJ (2004) Future climate change of the subtropical North Atlantic: implications for the cloud forests of tenerife. Clim Change 65:103-123. https://doi.org/10.1023/ B:CLIM.0000037488.33377.bf

Publisher's Note Springer Nature remains neutral with regard to jurisdictional claims in published maps and institutional affiliations.

\section{Affiliations}

\section{Alejandro G. Fernández de Castro ${ }^{1}$ (D) . Vicente $\operatorname{Rozas}^{2,5}$ (D) Javier Fuertes-Aguilar ${ }^{1}$ (D) . Juan Carlos Moreno-Saiz ${ }^{3,4}$ (i)}

Javier Fuertes-Aguilar

jfuertes@rjb.csic.es

Juan Carlos Moreno-Saiz

jcarlos.moreno@uam.es

1 Departamento de Biodiversidad y Conservación, Real Jardín Botánico-CSIC, Calle Claudio Moyano 1, 28013 Madrid, Spain

2 iuFOR-EiFAB, Campus Duques de Soria, Universidad de Valladolid, Campus Duques de Soria, 42004 Soria, Spain

3 Departamento de Biología (Botánica), Universidad Autónoma de Madrid, Calle Darwin 2, 28049 Madrid, Spain

4 Centro de Investigación en Biodiversidad y Cambio Global (CIBC-UAM), Universidad Autónoma de Madrid, 28049 Madrid, Spain

5 Laboratorio de Dendrocronología y Cambio Global, Facultad de Ciencias Forestales y Recursos Naturales, Universidad Austral de Chile, Valdivia, Chile 